\title{
Health coaching for glaucoma care: a pilot study using mixed methods
}

This article was published in the following Dove Press journal:

Clinical Ophthalmology

22 October 2015

Number of times this article has been viewed

\author{
Anita Vin' \\ Suzanne Schneider ${ }^{2}$ \\ Kelly W Muir ${ }^{1,3}$ \\ Jullia A Rosdahl'
}

'Department of Ophthalmology, Duke University, Durham, NC, ${ }^{2}$ Department of Health Philosophy and Promotion, Maryland University of Integrative Health, Laurel, MD, ${ }^{3}$ Durham VA

Medical Center, Durham, NC, USA
Correspondence: Jullia A Rosdahl

235I Erwin Road, Duke University

Medical Center, DUMC Box no 3802,

Durham, NC 27710, USA

$\mathrm{Tel}+\mathrm{I} 9196848850$

Fax + I91968I8267

Email jullia.rosdahl@duke.edu
Introduction: Adherence to glaucoma medications is essential for successful treatment of the disease but is complex and difficult for many of our patients. Health coaching has been used successfully in the treatment of other chronic diseases. This pilot study explores the use of health coaching for glaucoma care.

Methods: A mixed methods study design was used to assess the health coaching intervention for glaucoma patients. The health coaching intervention consisted of four to six health coaching sessions with a certified health coach via telephone. Quantitative measures included demographic and health information, adherence to glaucoma medications (using the visual analog adherence scale and medication event monitoring system), and an exit survey rating the experience. Qualitative measures included a precoaching health questionnaire, notes made by the coach during the intervention, and an exit interview with the subjects at the end of the study.

Results: Four glaucoma patients participated in the study; all derived benefits from the health coaching. Study subjects demonstrated increased glaucoma drop adherence in response to the coaching intervention, in both visual analog scale and medication event monitoring system. Study subjects' qualitative feedback reflected a perceived improvement in both eye and general health self-care. The subjects stated that they would recommend health coaching to friends or family members

Conclusion: Health coaching was helpful to the glaucoma patients in this study; it has the potential to improve glaucoma care and overall health.

Keywords: motivation, behavior change, adherence, medication, health

\section{Introduction}

Open-angle glaucoma is a chronic eye disease that currently affects $>2$ million individuals in the United States; the number is projected to grow to $>3$ million by $2020 .^{1}$ It is particularly concerning that poorly controlled glaucoma can lead to blindness. The personal and public health implications of this disease provide an urgency to optimize both delivery of care and patient self-care.

Poor adherence to treatment regimens is a commonly observed problem in many chronic medical diseases. ${ }^{2}$ Given the asymptomatic nature of glaucoma and the effort required for daily eye drop treatment, patients are at risk for low adherence. Consistent lowering of intraocular pressure is associated with slowed progression of visual field loss and optic nerve damage, ${ }^{3-5}$ and therefore, eye drop adherence is a crucial component of maintaining a glaucoma patient's vision.

Recent studies evaluating barriers to glaucoma medication adherence have revealed a theme: glaucoma patients are a heterogeneous group with diverse reasons for nonadherence. ${ }^{6}$ Tsai et $\mathrm{al}^{7}$ categorized these barriers to adherence under four distinct taxonomies: regimen factors (cost of medication, side effects, complexity of regimen), patient factors (skill in administration, memory, health beliefs), provider 
factors (dissatisfaction, communication), and situational/ environmental factors (lack of support, travel).

Clearly, addressing the unique challenges of adherence would require a tailored, patient-centered approach. Health coaching is a method used to help individuals develop and improve health management skills and to achieve greater well-being by aligning their vision of optimal health with practical health-oriented goals. It can provide new ways of engaging patients in their own health and helping them with accountability. Coaching encourages patients to tap into their creativity to find their own unique solutions to their health challenges. ${ }^{8}$ It can be done over the telephone, potentially reaching patients who may not be able to travel for more conventional, in-person behavioral interventions. Health coaching has been shown to improve adherence in other chronic diseases such as diabetes and hypertension, ${ }^{9}$ but it has not yet been used for glaucoma management.

Since the potential of health coaching in improving glaucoma patient self-care has never before been explored, our pilot study centers around the question: how can we support our patients to best integrate glaucoma self-care into their daily lives? Our hypothesis is that health coaching will improve eye drop adherence and patient engagement with self-care. The purpose of this study was to test the feasibility of health coaching for glaucoma patients and refine a health coaching model for glaucoma.

\section{Methods}

\section{Study subjects}

Study subjects were recruited from the Duke Eye Center Glaucoma Service, a tertiary glaucoma clinic, in
2014. Inclusion criteria were adult (age $>18$ years) glaucoma patients who were currently taking at least one topical glaucoma eye medication for at least 6 months, primarily administering the drops themselves, English speaking, and able to use the telephone for the coaching intervention. Patients who were likely to need glaucoma surgery or laser during the 6 months of the study period were excluded from this study. Subjects received two parking vouchers for the study-related visits and a \$20 honorarium if all parts of the study were completed.

Nine patients were consented, and four completed the coaching intervention and all study activities. Of the five who did not complete the study, four withdrew prior to the coaching intervention and one during the initial coaching session; reasons for withdrawal were lack of sufficient time to participate in the coaching intervention.

\section{Study design}

This prospective pilot study (overview in Figure 1) was approved by the Duke University Institutional Review Board and was registered with the National Institutes of Health (NCT02090777). A mixed methods study design was used to collect qualitative and quantitative data throughout the study duration. After informed consent was obtained, subjects completed an intake survey (Figure S1) that included demographic information and ophthalmic history, a visual analog scale of medication adherence, ${ }^{10}$ and a cognitive screen. ${ }^{11}$ Subjects were given a medication event monitoring system (MEMS) to be used with their most frequently dosed glaucoma medication and instruction on use of the system for the duration of the study ( $\sim 6$ months).

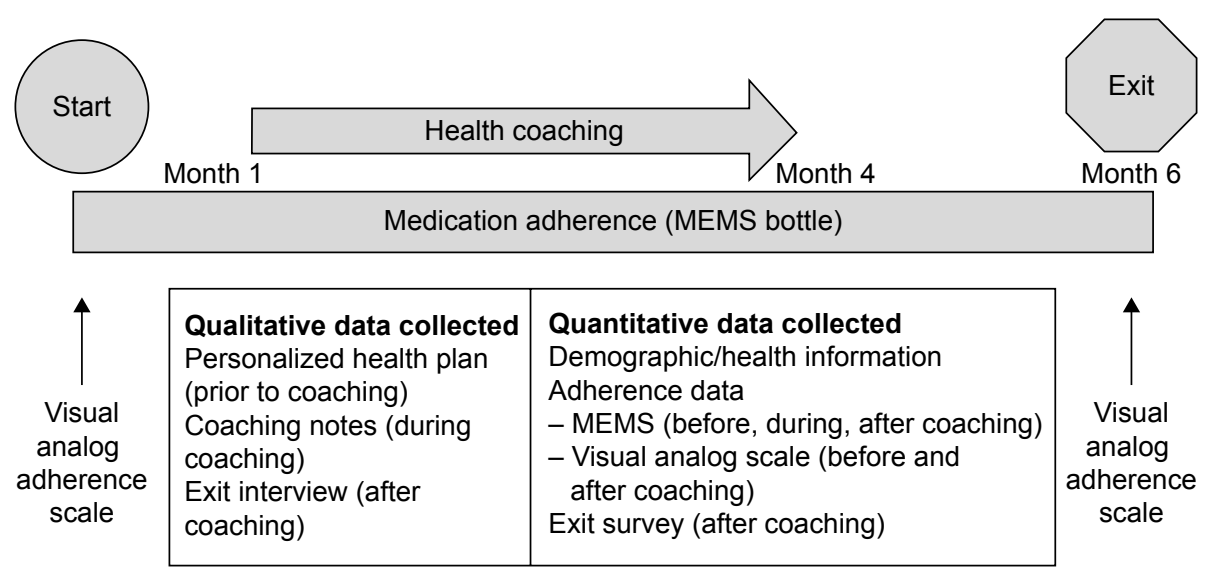

Figure I Study overview.

Notes: This pilot study consisted of a mixed methods study design, to collect both qualitative and quantitative data. At the initial visit, informed consent was obtained, demographic and health information was collected, and the visual analog adherence scale was used to assess glaucoma medication adherence. The study subject then began using the MEMS device, which continued for the duration of the study (6 months). The first health coaching session took place after I month; subsequent coaching sessions were completed over the following 2-4 months. After completion of the health coaching session, the study subject continued using the MEMS device until the end of the study. During the exit visit, the MEMS device was returned, a short survey was completed, and a 0.5-hour exit interview was conducted.

Abbreviation: MEMS, medication event monitoring system. 
A personal health plan questionnaire (Figure S2) was given to each subject at the initial visit, with a stamped, addressed envelope, to be completed by him or her and mailed to the health coach prior to the first coaching session. Seven days to ten days following the initial visit, the health coach called the subject to schedule the first coaching session and to confirm use of the MEMS device. The initial coaching session was scheduled 1 month following the initial visit, and the intervention is described in detail below. An exit visit was scheduled for 6 months after the initial visit, with flexibility to coordinate with a clinical visit to the eye center. At the exit visit, the MEMS bottle was returned, an exit survey was completed (Figure S3) to quantitatively assess the health coaching intervention and study experience, and an exit interview was done (interview guide, Figure S4). The exit interviews were recorded and transcribed for analysis.

\section{Health coaching intervention}

The health coaching intervention lasted approximately 3 months and was done with a certified health coach based on the Duke Integrative Health Coaching model. ${ }^{12}$ Standard to a health coaching experience is a personal health plan, completed prior to the first coaching session and mailed to the coach. The intervention consisted of an introductory session with the health coach ( $\sim 1$ hour) where the coach reviewed the coaching process and the personal health plan and started to explore the areas of vision or general health identified by the study subject. The subsequent sessions lasted $\sim 45$ minutes, every $2-4$ weeks.

The coaching process used open-ended questions, reflective listening techniques, and behavior change methodologies such as Motivational Interviewing ${ }^{13}$ to explore opportunities and barriers to behavior change in relation to the subject's health vision and life values. While this general model was used throughout the study coaching intervention, the coach checked in about eye health at each session. All the coaching sessions were carried out over the telephone; the coach made notes during the sessions, as a part of her routine coaching practice.

\section{Assessment of medication adherence}

Glaucoma medication adherence was assessed using the MEMS device and a visual analog adherence scale. The MEMS device is a pill bottle and cap, where the cap consists of an electronic monitor that records the date and time each time the subject opens the bottle. The bottle within a bottle method ${ }^{14}$ was used in this study, whereby the subject placed his or her eye drop bottle inside the MEMS device (the bottle and cap); each time the subject opened the MEMS device to take out and use his or her eye drops, the device recorded the date and time. At the end of the study, the MEMS devices were collected and the adherence information was uploaded. For the MEMS device, the percent adherence or percent of prescribed doses taken was calculated each of the following time periods: precoaching (study start to first coaching session), during coaching (first coaching session to last coaching session), and postcoaching (last coaching session to exit visit). For example, if a patient was prescribed latanoprost to be taken daily for 30 days and the MEMS bottle revealed only 15 openings, the percent of prescribed doses taken would be $50 \%$. Subject 3 is not included in the figure of the data because this study subject began monitoring medication use using a different method (a personal spread sheet) during the coaching portion of the study, so MEMS data are not available for this study subject. For the visual analog adherence scale, the study subjects completed the scale at the initial visit and at the exit visit. The subjects noted the percentage of time the prescribed glaucoma medication is used as directed, by marking on a line between none of the time and all of the time. For example, if a patient makes a mark halfway, the percent adherence would be $50 \%$.

\section{Qualitative data collection and analysis}

The qualitative portion of this study draws from three data sources: 1) personal health plan, completed by subjects when they first enrolled in the study; 2) coaching notes, completed by the study coach to document details of each coaching session; and 3) semi-structured exit interviews, completed with each study subject at the end of the study, after completion of their coaching sessions. Content analyses of the personal health plan, coaching notes, and exit interviews were conducted to develop comprehensive profiles of individual subjects, their health coaching experience, and their behavior changes and to generate patterns and themes from aggregate data. We examined subject profiles and aggregate data themes to elicit trends regarding eye drop adherence, coaching efficacy, and study experience.

\section{Results}

This pilot study included four glaucoma patients (Table 1) who were using glaucoma eye drop medications. All had moderate or severe stage glaucoma, and one met criteria for legal blindness (based on visual field criteria). Each had been using glaucoma eye drop medications for at least 5 years. All identified some type of barrier to adherence, including forgetting drops (all subjects noted mild or some effect) and side effects of drops (one subject noted some effect); cost was not identified as a barrier for the subjects of this pilot study. Three of the four subjects were taking other chronic medications. 
Table I Characteristics of study subjects

\begin{tabular}{ll}
\hline $\begin{array}{l}\text { Demographics } \\
\text { Age (mean) }\end{array}$ & 73 years (range 69-83) \\
Sex & 3 male subjects and I female subject \\
Race & 2 white subjects and 2 black subjects \\
$\begin{array}{l}\text { Glaucoma history } \\
\text { Type of glaucoma }\end{array}$ & POAG (2 subjects) \\
& CACG (I subject) \\
& PDG (I subject) \\
Severity of glaucoma & Moderate $(2$ subjects) \\
Number of glaucoma & Severe (2 subjects) \\
medications (mean) & 2.8 medications (range 2-3) \\
History of glaucoma surgery & I subject (glaucoma tube surgery) \\
History of glaucoma lasers & 3 subjects \\
Visual impairment & I subject (based on visual field criteria) \\
Legal blindness & $20 / 20$ (3 subjects) \\
BCVA in better-seeing eye & $20 / 70$ (I subject) \\
Perception of visual & I00\% \\
impairment & Almost no effect (2 subjects) \\
Perceived severity & Mild effect (I subject) \\
& Some effect (I subject) \\
General medical history & Hypertension (3 subjects) \\
Medical problems & None with diabetes \\
Use of other chronic & 3 subjects \\
medications & \\
\hline
\end{tabular}

Note: aBased on ICD-9 codes for glaucoma severity.

Abbreviations: POAG, primary open-angle glaucoma; CACG, chronic angle closure glaucoma; PDG, pigment dispersion glaucoma; BCVA, best-corrected visual acuity; ICD-9, International Classification of Diseases, ninth revision.
None of the subjects had experience with a health coach prior to the study; at the study start, the health coaching intervention was perceived to be probably not helpful (one subject), maybe or maybe not helpful (two subjects), and probably helpful (one subject). Based on a cognitive screen, two of the four subjects may have had some memory impairment, not unanticipated given the older patient population.

\section{Effect of health coaching on glaucoma medication adherence}

Glaucoma medication adherence as measured by the MEMS device (Figure 2A) varied among the study subjects, from $67 \%$ to $98 \%$ adherence (percent of prescribed doses taken) at the beginning of the study. Two study subjects had high rates of medication adherence throughout the study (Study Subjects 2 and 3) although Study Subject 3 stopped using the study device and tracked his medication usage with a personal spreadsheet (data not shown). Study Subjects 1 and 4 showed improved adherence post coaching compared with during coaching: $67 \%$ to $78 \%$ (for Subject 1 ) and $66 \%$ to $86 \%$ (for Subject 2). The initial dip seen with Subject 1 may be due to normalization of a boost in adherence at study start.

Glaucoma medication adherence measured by the visual analog adherence scale (Figure 2B) was similar overall to that measured with the MEMS device. Subjects 1, 3, and 4 show improved adherence at the exit visit compared with
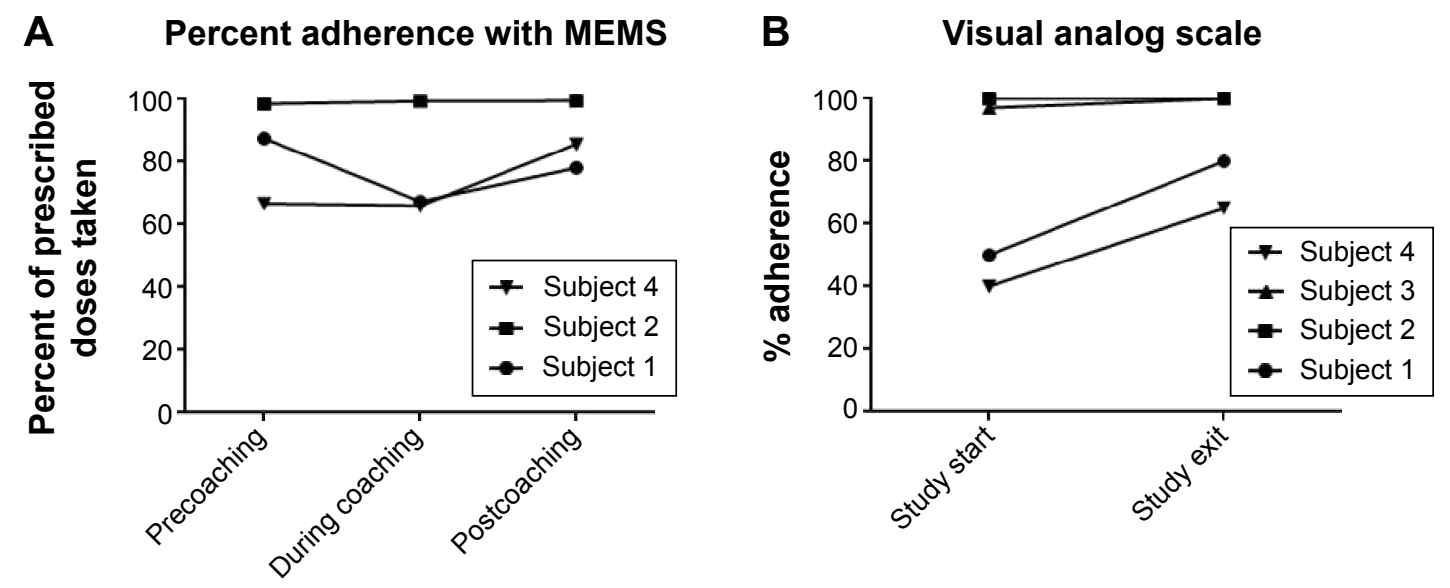

Figure 2 Glaucoma medication adherence.

Notes: (A) Glaucoma medication adherence was assessed using the MEMS device. The percent adherence or percent of prescribed doses taken was calculated each of the following time periods: precoaching (study start to first coaching session), during coaching (first coaching session to last coaching session), and postcoaching (last coaching session to exit visit). The adherence data for each subject are plotted over time to illustrate their measured adherence. Subject 3 is not included in this figure because this study subject began monitoring medication use using a different method (a personal spread sheet) during the coaching portion of the study; hence, MEMS data are not available for this study subject. Study Subjects I and 4 show improved adherence postcoaching compared with during coaching. The dip seen with Study Subject I is likely due to normalization after a boost at study start. Study Subject 2 has high adherence throughout. (B) Glaucoma medication adherence was assessed using the visual analog adherence scale, with study subjects completing the scale at the study start and at the exit visit. The adherence data for each subject are plotted at study start and end to illustrate their measured adherence. Study Subjects I, 3, and 4 show improved adherence at the exit visit compared with the study start, although Study Subject 3 has high adherence at the outset. Study Subject 2 has high adherence throughout. Overall, the adherence measured with the visual analog adherence scale is similar to that measured with the MEMS device.

Abbreviation: MEMS, medication event monitoring system. 
the study start $(50 \%$ to $80 \%$, Subject $1 ; 97 \%$ to $100 \%$, Subject 3; $40 \%$ to $65 \%$, Subject 4 ), although Subject 3 has high adherence at the outset. Subject 2 has high adherence throughout (100\%).

\section{Qualitative summary of coaching outcomes}

Subject 1 experienced his gradual loss of eyesight as a direct loss of autonomy. His passion was reading the Bible, and he struggled with relying on others to read to him. He used his coaching sessions to explore ways to access visual aid resources that might help restore some of his autonomy. At the conclusion of his coaching session, he noted that coaching helped him become more aware "that there are some things that you may not have a knowledge of that you really need to identify". He appreciated the space that coaching offered to consider his options and renew his commitment for finding solutions, as he said, "I think I had gotten to a point of taking things for granted in a sense and the coaching sessions sort of opened up another light". The sessions helped him recognize that he needed to gather more information and remain optimistic about the things he could control.

Subject 2 felt that he was doing a great job with eye health; he was making his appointments and remembering the majority of his eye drops. Early in the coaching, he was struggling to remember his morning eye drops because he felt rushed in the morning. By the second session, this issue had been resolved. However, the issues of perpetually feeling rushed, overcommitted in his work, and lacking personal time were weighing on him. He felt that his busyness was affecting his relationships, his weight, and his overall well-being. His coaching sessions therefore were focused on developing a plan to decrease his professional obligations and reprioritize self- and family-time with the hopes that it could help him lose weight and find greater balance. For him, coaching:

[...] made me think about what I was doing. I finally decided

I was going to do something about weight control. I was

going to take more time off and force the issue that I needed

more time off. It has resulted in a more balanced lifestyle.

Basically, I have more time for my family.

Subject 3 was struggling with applying eye drops three times a day. He was convinced he needed to space the drops at equal intervals throughout each 24-hour period, which meant that he would need to wake himself up in the middle of the night to apply one of the drops. He would often forget in the morning if he administered this drop. Despite having been told by his health providers that he could space his drops throughout his waking hours, he still felt committed to a 24-hour spacing effort. Coaching offered him some focused time to work through his challenges with the drops. In the process of coaching, he developed a solution to his dilemma. He created (by hand) a wooden block with three holes where he could place his bottle that indicated which drop he had administered last. This helped him know with certainty which drop was next, even if he did not remember waking in the night. He also arrived at the conclusion through coaching that he could be more flexible in his eye drop adherence. This meant that he was willing to space the three drops during the day, eliminating the confusion of the night drop. His wooden block helped him stay on track and served as a reminder for taking his drops.

Subject 4 had been using eye medication for her glaucoma for $>40$ years. While she was used to the daily requirements of the drops, she still struggled to adhere to the midday drop because it required her to pause and sit with her eyes closed for a period of time, which she felt disruptive to her schedule. She chose to focus two of her coaching sessions on addressing barriers to the midday drop and developed concrete plans for when she had troubles pausing for the drops. The other coaching sessions were focused on healthy eating and exercise. Her 70th birthday came at the midpoint of her coaching, and she was committed to remaining active and healthy. She wanted to embrace the aging process while also acknowledging the limitations that came with aging, which she felt were acceptable as long as she remained active. By the end of the coaching, she had cut down on breads, was eating more vegetables, and was focusing on healthy eating vs dieting. She also had reengaged in an exercise program at the senior citizens center. At the conclusion of her coaching, she felt it helped her "get focused on some things that I hadn't thought about before". More than anything, however, she felt that just being able to talk through some of her issues had a "positive effect on my overall well-being".

\section{Quantitative assessment of the intervention and recommendations}

Overall, the health coaching was found to be helpful by the study subjects, and most would recommend it to a friend or family member with a chronic disease or with glaucoma. The length and number of coaching sessions was on target, and study subjects said that they would participate in health coaching in a variety of settings: group sessions (75\%), in person $(50 \%)$, by phone $(75 \%)$, and Internet (50\%). A summary of recommendations from the study subjects and team is presented in Table 2. 
Table 2 Recommendations for improvement

\section{Improve the description of health coaching}

There was a general lack of clarity on the part of the study subjects on what health coaching is, persisting even to the exit visit, suggesting that the introduction of the study by the study-team, the study take-home documents, and the introduction by the health coach were not adequate. A video with an example of a coaching conversation would likely be helpful in the future.

\section{Focus on the eye drops}

The health coaching intervention in this pilot study was purposefully left broad, allowing the study subject to guide the coaching conversation onto focus areas of their choice to see what aspects of health coaching would be helpful for glaucoma patients. At least once per session, the health coach touched on glaucoma and ocular health, but otherwise, the focus areas and coaching goals were guided by the study subject entirely. At the close of the study, the subjects noted that more direction and greater focus on eye drops would be helpful in refining the coaching intervention.

Target patients with poor adherence

Health coaching will likely be more helpful with patients who are struggling with medication adherence. However, two of the study subjects had high adherence, but still made significant gains due to the health coaching, even with regard to glaucoma care.

Train an ophthalmic technician or experienced glaucoma patient as a health coach

A health coach with additional glaucoma knowledge may help keep the focus on glaucoma care and may be able to offer additional information and resources, in addition to the coaching support. ${ }^{16}$

Offer the coaching to newly diagnosed patients

Patients new to eye drops likely need additional support. Addressing any barriers to medication adherence as early as possible would help to establish lifelong healthy habits and improve visual outcomes.

\section{Discussion}

In summary, study subjects demonstrated increased glaucoma drop adherence in response to the coaching intervention, from both self-reported adherence rates as well as with MEMS. Study subjects' qualitative feedback reflected a perceived improvement in both eye health and general health self-care. Finally, patients felt that the coaching experience effected enough positive change that they would recommend friends or family members to participate in health coaching.

Older patients, especially those with visual impairment, frequently have multiple medical problems, ${ }^{15}$ and all of our study subjects had at least one other chronic medical problem requiring medication besides glaucoma. Health coaching has the potential to impact all aspects of health ${ }^{8}$ for patients. Many factors can influence the health coaching process, including age, sex, personality, and cognitive function. The health coaching intervention used in this exploratory study was open-ended, allowing subjects to direct the coaching focus, and showed benefits both in eye health and general health. While our sample is too small to make conclusions with regard to the other medical issues, it does suggest that the coaching helped glaucoma patients place more attention on lifestyle factors rather than medical conditions; this implies that coaching could help these patients attend better to their medical conditions. Following up on the effect of health coaching on nonglaucomatous medical conditions would be of interest in future studies.

Each of these patients described a unique experience in relation to living with glaucoma and adhering to his or her eye drop regimen. While one patient struggled with administering the morning drop because of busyness, another struggled with middle of the night drop because of the perception that the drops needed to be spaced evenly within 24 hours. A third patient struggled with the midday drop because it was disruptive to her schedule. Three of the patients were retired and felt that their lack of routine schedules made it difficult to adhere to an eye drop regimen. One of the patients described the hostile relationship she had developed with her eye drop bottle because she found it to be a constant reminder of her disease. In other words, the challenges that our subjects faced in eye drop adherence were unique to their schedules, lifestyles, views on compliance, and perceptions of their disease.

Yet despite these differences, all subjects shared a concern for their loss of autonomy in relation to their glaucoma experience. They each described how important their independence was in order to read, use computers, drive, and recognize and engage with people. They all answered the questions: "What is most important to you as you think about your Overall Health?" and "What is most important to you as you think about your Optimal Vision?" with a focus on independence and autonomy. Given that this is an aging population $(60+)$, it is not surprising that autonomy is perceived to relate directly to one's overall health and vision. Yet this may be overlooked by a medical system that focuses largely on physical aspects of health rather than the wider circumstances surrounding well-being.

While our medical system offers tools to help limit or slowdown vision loss, it does not always acknowledge the double-edged sword of glaucoma and aging, which may amplify the anticipation of, or the true loss of, autonomy. Nor can health providers always recognize the unique struggles that patients undergo as they try to manage their disease and comply with their eye drop regimen within the context of complex individual lives, barriers, perceptions, and beliefs. 
Our study suggests that these unique experiences warrant a personalized health approach and that health coaching could help patients navigate their disease more effectively.

There are limitations to this pilot study. A small number of glaucoma patients participated in the study; thus, the results may not be generalizable. Of note, of nine recruited patients, five dropped out prior to completing the study, the majority prior to even starting the coaching; an understanding of the reasons behind this dropout rate would help significantly in tailoring future recruitment efforts. The study duration was 6 months, and persistent effects from coaching were not assessed. Additionally, all the subjects received coaching and there was no control group. Effects on physiology, such as intraocular pressure changes or weight changes, were not measured. The effects of the health coaching were assessed using a comprehensive evaluation based on precoaching values exercise (personal health plan questionnaire), coaching notes (taken during the coaching), and subject recall (during the exit interview).

The mixed methods used for this pilot study enabled us not only to pilot test the intervention using quantitative methods planned for larger follow-up studies, but also, using qualitative methods, to explore the unique effects of health coaching on these initial subjects and to share these findings with the larger community, adding to the work of those developing other interventions. We believe that these findings will be of interest to doctors and researchers pursuing ways to motivate glaucoma patients in the care of their disease.

This pilot study examined the feasibility of a larger scale health coaching endeavor among glaucoma patients. Future directions include refining the health coaching intervention and performing a larger study to examine efficacy in this population. In addition, training physicians, ophthalmic nurses, or technicians well-versed in glaucoma on concepts of health coaching may be helpful to glaucoma patients. The potential cost of health coaching to an overburdened health-care system could be offset by utilizing and training individuals at the front lines of patient care, and perhaps offering coaching in a group, by phone, or in-person setting to tailor the coaching intervention to the needs of glaucoma patients. Health coaching has the potential to improve glaucoma care and overall health.

\section{Acknowledgments}

The authors acknowledge the invaluable assistance of Ms Patricia Barbour for transcription of the interviews and
Ms Christina Bunn for study recruitment and regulatory assistance. This study was funded by a Mentoring for Advancement of Physician-Scientists award from the American Glaucoma Society.

\section{Disclosure}

KWM receives salary support from a VA HSR\&D career development award. The authors declare that they have no conflicts of interest related to this work.

\section{References}

1. Friedman DS, Wolfs RC, O'Colmain BJ, et al. Prevalence of openangle glaucoma among adults in the United States. Arch Ophthalmol. 2004;122(4):532-538.

2. DiMatteo MR. Variations in patients' adherence to medical recommendations: a quantitative review of 50 years of research. Med Care. 2004;42(3):200-209.

3. The Advanced Glaucoma Intervention Study (AGIS): 7. The relationship between control of intraocular pressure and visual field deterioration. The AGIS Investigators. Am J Ophthalmol. 2000;130(4):429-440.

4. Kass MA, Heuer DK, Higginbotham EJ, et al. The ocular hypertension treatment study: a randomized trial determines that topical ocular hypotensive medication delays or prevents the onset of primary openangle glaucoma. Arch Ophthalmol. 2002;120(6):701-713. [discussion 829-830].

5. Lichter PR, Musch DC, Gillespie BW, et al. Interim clinical outcomes in the collaborative initial glaucoma treatment study comparing initial treatment randomized to medications or surgery. Ophthalmology. 2001; 108(11):1943-1953.

6. Tsai JC. A comprehensive perspective on patient adherence to topical glaucoma therapy. Ophthalmology. 2009;116(11 suppl):S30-S36.

7. Tsai JC, McClure CA, Ramos SE, Schlundt DG, Pichert JW. Compliance barriers in glaucoma: a systematic classification. J Glaucoma. 2003; 12(5):393-398.

8. Moore M. Coaching the multiplicity of mind: a strengths-based model. Glob Adv Health Med. 2013;2(4):78-84.

9. Thom DH, Willard-Grace R, Hessler D, et al. The impact of health coaching on medication adherence in patients with poorly controlled diabetes, hypertension, and/or hyperlipidemia: a randomized controlled trial. J Am Board Fam Med. 2015;28(1):38-45.

10. Sleath BL, Blalock SJ, Muir KW, et al. Determinants of self-reported barriers to glaucoma medicine administration and adherence: a multisite study. Ann Pharmacother. 2014;48(7):856-862.

11. Whitson HE, Whitaker D, Potter G, et al. A low-vision rehabilitation program for patients with mild cognitive deficits. JAMA Ophthalmol. 2013;131(7):912-919.

12. Wolever RQ, Caldwell KL, Wakefield JP, et al. Integrative health coaching: an organizational case study. Explore (NY). 2011;7(1):30-36.

13. Miller WR, Rollnick S. Motivational Interviewing: Helping People Change. 3rd ed. New York: The Guilford Press; 2013.

14. Robin AL, Novack GD, Covert DW, Crockett RS, Marcic TS. Adherence in glaucoma: objective measurements of once-daily and adjunctive medication use. Am J Ophthalmol. 2007;144(4): 533-540.

15. Court H, McLean G, Guthrie B, Mercer SW, Smith DJ. Visual impairment is associated with physical and mental comorbidities in older adults: a cross-sectional study. BMC Med. 2014;12:181.

16. Cook PF, Bremer RW, Ayala AJ, Kahook MY. Feasibility of motivational interviewing delivered by a glaucoma educator to improve medication adherence. Clin Ophthalmol. 2010;4:1091-1101. 


\section{Supplementary materials}

\begin{tabular}{|c|c|c|c|c|}
\hline \multicolumn{5}{|c|}{ Patient portion (to be completed with study-team member): } \\
\hline 1. What type of glaucoma do you have? & \multicolumn{3}{|l|}{ Description: } & ICD-9 code: \\
\hline $\begin{array}{l}\text { 2. For how many years have you used drops } \\
\text { for glaucoma? }\end{array}$ & $\begin{array}{l}\text { Less than } 1 \text { year }(1) \\
1-5 \text { years }(2) \\
5-10 \text { years }(3) \\
\text { Greater than } 10 \text { years }(4)\end{array}$ & & & $\begin{array}{l}\text { \# years (if } \\
\text { known) }\end{array}$ \\
\hline $\begin{array}{l}\text { 3. Have you ever had eye surgery for } \\
\text { glaucoma? } \\
\text { If so, what type? }\end{array}$ & \multicolumn{3}{|l|}{$\begin{array}{l}\text { Yes (1) } \\
\text { No (0) } \\
\text { Unsure (2) }\end{array}$} & $\begin{array}{l}\text { Types of } \\
\text { surgery: }\end{array}$ \\
\hline $\begin{array}{l}\text { 4. Have you ever had laser for glaucoma? } \\
\text { If so, how many times? }\end{array}$ & \multicolumn{3}{|l|}{$\begin{array}{l}\text { Yes (1) } \\
\text { No (0) } \\
\text { Unsure (2) }\end{array}$} & \# of times: \\
\hline $\begin{array}{l}\text { 5. Do you have any other eye diseases } \\
\text { (like macular degeneration or diabetic } \\
\text { retinopathy)? } \\
\text { If so, what other eye diseases? }\end{array}$ & \multicolumn{3}{|l|}{$\begin{array}{l}\text { Yes }(1) \\
\text { No }(0) \\
\text { Unsure (2) }\end{array}$} & $\begin{array}{l}\text { If other, please } \\
\text { list: }\end{array}$ \\
\hline $\begin{array}{l}\text { 6. Do you feel that you have vision loss } \\
\text { from glaucoma? }\end{array}$ & \multicolumn{3}{|c|}{$\begin{array}{l}\text { If yes: On a scale of } 1-5 \text {, how severe is your vision loss? } \\
1 \text { Almost no effect on my life } \\
2 \text { Mild effect } \\
3 \text { Some effect } \\
4 \text { Frequently } \\
5 \text { It has changed my life completely }\end{array}$} & \\
\hline $\begin{array}{l}\text { 7. Have you had a health or life coach } \\
\text { before? } \\
\text { If so, what type? }\end{array}$ & \multicolumn{3}{|l|}{$\begin{array}{l}\text { Yes, Health coach (1) } \\
\text { Yes, other (2) } \\
\text { No }(0)\end{array}$} & $\begin{array}{l}\text { If other, what } \\
\text { type: }\end{array}$ \\
\hline $\begin{array}{l}\text { 8. Do you have barriers to using your } \\
\text { glaucoma drops as prescribed? } \\
\text { (Does anything keep you from using your } \\
\text { eye drops like you are supposed to?) }\end{array}$ & \multicolumn{3}{|c|}{$\begin{array}{l}\text { No barriers ( } 0) \\
\text { Occasional barrier, but not significant (1) } \\
\text { Some barriers, but getting by (2) } \\
\text { A lot of barriers, difficult for me (3) } \\
\text { So many barriers, unable to count (4) }\end{array}$} & \\
\hline $\begin{array}{l}\text { 9. How much does — keep you from using } \\
\text { your eye drops like you are supposed to? } \\
\text { Cost of medications } \\
\text { Forgetting } \\
\text { Eye side effects like discomfort/redness/ } \\
\text { blurry vision } \\
\text { Other (anything else) }\end{array}$ & $\begin{array}{l}\text { Cost } \\
\text { No effect (0) } \\
\text { Mild (1) } \\
\text { Some (2) } \\
\text { Moderate (3) } \\
\text { Significant/huge effect (4) }\end{array}$ & $\begin{array}{l}\text { Forgetting } \\
\text { No effect (0) } \\
\text { Mild (1) } \\
\text { Some (2) } \\
\text { Moderate (3) } \\
\text { Significant/huge effect (4) }\end{array}$ & $\begin{array}{l}\text { Side effects } \\
\text { No effect (0) } \\
\text { Mild (1) } \\
\text { Some (2) } \\
\text { Moderate (3) } \\
\text { Significant/huge effect (4) }\end{array}$ & $\begin{array}{l}\text { If other, } \\
\text { please } \\
\text { describe: }\end{array}$ \\
\hline $\begin{array}{l}\text { 10. Based on what you currently know about } \\
\text { Health Coaching, please tell us what effect } \\
\text { you think it will have on your ability to } \\
\text { take better care of your glaucoma. }\end{array}$ & $\begin{array}{l}\text { I feel strongly that it will } 1 \\
\text { It will probably help (4) } \\
\text { Maybe or maybe not (3) } \\
\text { It probably will not help ( } \\
\text { I feel strongly that it will }\end{array}$ & tp me (5) & & \\
\hline 11. Adherence scale & \multicolumn{3}{|c|}{ Study subject to mark on page 2.} & \\
\hline 12. Cognitive scale & \multicolumn{3}{|c|}{ Note study subject responses on page 3.} & \\
\hline \multicolumn{5}{|c|}{ All things considered, how much of the time do you use ALL of your glaucoma medications EXACTLY as directed? } \\
\hline \multicolumn{5}{|c|}{ Place a mark (1) anywhere on the line below to indicate your answer. } \\
\hline None of the time & & & All of the time & \\
\hline
\end{tabular}

Figure SI (Continued) 


\section{Eye clinic cognitive screen}

1) Now I am going to read to you 10 words from this paper. Listen to them and repeat each word after me. Remember these words. I will ask you to recall these words later.

Read this list in a slow, steady tone. Articulate carefully and have the patient repeat each word after you say it. Correct the patient if he mis-heard you and have him repeat the correct word:

$\begin{array}{llll}\text { Target } & \text { Finger } & \text { Sunset } & \text { Crocodile } \\ \text { Dollar } & \text { Yard } & \text { Student } & \text { Traffic }\end{array}$

Broom Ocean

"Now please tell me as many of those words as you can remember".

If the patient stops, you can prompt with "Do you remember any more? It's all right to guess, even if you're not sure". Do not acknowledge whether responses are correct or not. If the patient asks you can say "I'm not allowed to tell you whether the word was on the list or not, but you are doing just fine".

Record all responses here:

No correct

2) Now I'm going to say a letter and I want you to name all the words you can think of that start with that letter. You'll have 60 seconds. Please don't use proper nouns like the names of people or places, so if the letter were R, you wouldn't say Rochester or Robert, just ordinary words. Also, try not to say the same word over and over with a different ending like run, runner, running, runs. Ready? When I give you the letter, you'll have 60 seconds. The letter is "F".

If needed, you can remind them of instructions: "remember no names - only ordinary words".

No correct (POSITIVE SCREEN $\leq 10)$

3) Now, I'd like you to think back to that list of 10 words that I read to you earlier. Can you remember any of the words from that list? It's ok to guess.

No correct

Add \#1 and \#3 scores. TOTAL \#1+\#3:

(POSITIVE SCREEN $\leq 6)$

Figure SI (Continued) 


\begin{tabular}{|c|c|}
\hline MD portion (to be completed by PI) & \\
\hline Glaucoma Type (description) & \\
\hline Glaucoma Type (ICD-9) code & \\
\hline Severity & Severe (4) \\
\hline & Moderate (3) \\
\hline & Mild (2) \\
\hline & Suspect (1) \\
\hline Meets criteria for legal blindness & Yes (1) \\
\hline & No $(0)$ \\
\hline & Insufficient data (2) \\
\hline Visual acuity at initial visit & OD \\
\hline & OS \\
\hline Best corrected visual acuity within in past 6 months & OD \\
\hline & OS \\
\hline \# years on glaucoma drops & Years \\
\hline $\mathrm{h} / \mathrm{o}$ glaucoma surgery & Yes (1) \\
\hline & No $(0)$ \\
\hline & Unsure (2) \\
\hline Prior glaucoma surgeries & List: \\
\hline h/o glaucoma laser & Yes (1) \\
\hline & No $(0)$ \\
\hline & Unsure (2) \\
\hline Prior glaucoma lasers & List: \\
\hline $\mathrm{h} / \mathrm{o}$ other eye disease & Yes (1) \\
\hline & No $(0)$ \\
\hline & Unsure (2) \\
\hline Other eye diseases & List: \\
\hline Primary cause of vision loss & No significant vision loss $(0)$ \\
\hline & Glaucoma (1) \\
\hline & Glaucoma plus another cause (2) \\
\hline & Non-glaucomatous cause (3) \\
\hline & Unsure (4) \\
\hline If non-glaucomatous contribution, what other diagno & \\
\hline Other medical problems? & None $(0)$ \\
\hline & Diabetes (1) \\
\hline & Hypertension (2) \\
\hline & Other (3) \\
\hline & If other, list: \\
\hline Other chronic medications? & None $(0)$ \\
\hline & Yes (1) \\
\hline
\end{tabular}

Figure SI Intake survey. 
All things considered, how much of the time do you use ALL of your glaucoma medications EXACTLY as directed?

Place a mark (1) anywhere on the line below to indicate your answer.

None of the time All of the time

1. Overall, please rate how helpful the Health Coaching experience was for you. Circle one number.
5
4
3
2
1

Very helpful Somewhat helpful

Not helpful at all

2. Please rate whether it was helped you with your glaucoma care. Circle one number.

5

Very helpful for my

glaucoma care
4

3

Somewhat helpful
1

Not helpful at all

3. Please rate whether you would recommend Health Coaching to a friend or family member with a chronic disease, like high blood pressure or diabetes. Circle one number.

5

Highly recommend to someone with high blood pressure

4. Please rate whether you would recommend Health Coaching to a friend or family member with glaucoma. Circle one number.

$$
5
$$

Highly recommend to

someone with glaucoma
4

Recommend in some cases
2

Would not recommend at all
Recommend in some cases
2

1

Would not recommend at all

5. How many coaching sessions did you complete? Check one box.
0 sessions
1-3 sessions
4-6 sessions
7-8 sessions
More than 8 sessions

6. Overall, how was the length of each coaching session? Check one box.

Much too short

About right

Much too long

7. Overall, how was the number of coaching sessions? Check one box.

Much too few

About right

Much too many

8. Please rate whether the coaching helped you to take your eye drops as directed. Circle one number.

5

Very helpful for taking my eye drops as directed

9. Please rate whether the coaching helped you to come to your glaucoma appointments as directed. Circle one number.

5

4

Very helpful for coming to appointments as directed

$$
4
$$

3

Somewhat helpful
2

Somewhat helpful
2
10. Health Coaching can be done in different settings.

Would you participate in Health Coaching in these settings?

Check ALL that apply.
In groups (6-10 people)

$\bigcirc$ In-person, individually

Over the telephone

Over the internet

Some other way. Please describe:

Figure S3 (Continued) 
11. If you knew then, what you know now, back when you were starting this study, would you still choose to participate? Circle one number.

5

Yes, for sure

12. How was it for you to use the electronic device to measure eye drop usage? Check one box.

Very easy

Neither easy nor hard

Very hard

13. What would you change about the coaching or the coaching sessions, to make the experience better for you or someone like you? Please write your answer here.

14. What would you change about the research study experience, to make it better for you or someone like you? Please write your answer here.

Figure S3 Exit survey. 


\section{The Health Coaching Experience}

1. What did you expect Health Coaching to be like prior to your first session?

2. To what extent was Health Coaching what you thought it would be?

3. What parts of the coaching experience were most valuable?

4. What parts of the coaching experience were the least helpful?

5. What changes did you make in your glaucoma care on account of coaching?

6. What changes did you make in other areas of your health on account of coaching?

7. Did you feel that the coaching experience had a positive impact on your overall wellness or health? (explain)

8. Did you feel that the coaching experience had any negative impacts on your overall wellness or health? (explain)

9. What aspects of the coaching did you enjoy the most?

10. What aspects of the coaching did you dislike?

\section{Health Coaching and Glaucoma}

11. What topics did you cover during the coaching sessions?

12. To what extent has there been any effect on your glaucoma care on account of coaching?

13. To what extent do you think Health Coaching could help glaucoma patients? (Explain)

14. What aspects of the Coaching do you think would be most helpful for glaucoma patients?

15. Is there anything that you would add to the coaching, or that you think would be really helpful, for glaucoma patients, compared with other chronic diseases?

\section{The Study Experience}

16. What was it like for you to be part of a research study?

17. What parts did you like about the research study?

18. What parts did you dislike about the research study?

19. What could we do to improve the experience for study subjects in the future?

Figure S4 Exit interview guide.

\section{Publish your work in this journal}

Clinical Ophthalmology is an international, peer-reviewed journal covering all subspecialties within ophthalmology. Key topics include: Optometry; Visual science; Pharmacology and drug therapy in eye diseases; Basic Sciences; Primary and Secondary eye care; Patient Safety and Quality of Care Improvements. This journal is indexed on

Submit your manuscript here: http://www.dovepress.com/clinical-ophthalmology-journal

\section{Dovepress}

PubMed Central and CAS, and is the official journal of The Society of Clinical Ophthalmology (SCO). The manuscript management system is completely online and includes a very quick and fair peer-review system, which is all easy to use. Visit http://www.dovepress.com/ testimonials.php to read real quotes from published authors. 